\title{
Acoustic Emission During Firing of the Illite-Based Ceramics with Fly Ash Addition
}

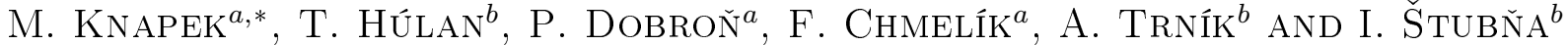
${ }^{a}$ Dept. of Physics of Materials, Charles University in Prague, Ke Karlovu 5, 12116 Prague, Czech Republic

${ }^{b}$ Dept. of Physics, Constantine the Philosopher University in Nitra, Tr. A. Hlinku 1, 94974 Nitra, Slovakia

In this work, illite-based ceramic body with power plant fly ash addition $(60 \mathrm{wt} . \%$ of illite, $30 \mathrm{wt} . \%$ of fly ash and 10 wt. $\%$ of illite fired at $1100{ }^{\circ} \mathrm{C}$ ) was investigated by the thermal analysis techniques (differential thermal analysis, thermodilatometry and thermogravimetry) and the acoustic emission technique. The green body was heated up to $1100{ }^{\circ} \mathrm{C}$ at three different rates $2.5,5,10 \mathrm{~K} / \mathrm{min}$. The most intense acoustic emission was recorded at the highest rate $10 \mathrm{~K} / \mathrm{min}$. Mutual correlations between thermal analyses and acoustic emission data were also examined. The first acoustic emission response appears at $430{ }^{\circ} \mathrm{C}$, corresponding to a small endotherm on the DTA curve, where the thermal decomposition of mineral portlandite takes place. In the temperature range from 600 to $900{ }^{\circ} \mathrm{C}$, high acoustic emission activity correlates with dehydroxylation and expansion of the sample. At temperatures higher than $800{ }^{\circ} \mathrm{C}$, the source of acoustic emission signals is the thermal decomposition of calcite. The amorphous phase created from illite at $920^{\circ} \mathrm{C}$ becomes pyroplastic, therefore it is not documented by the acoustic emission technique.
\end{abstract}

DOI: 10.12693 /APhysPolA.128.783

PACS: 64.70.ph, 61.43.Fs, 65.60.+a, 81.70.Pg, 43.40.Le

\section{Introduction}

Coal has been used for the production of electrical power for many decades. Fly ash is a non-burnable residue after combustion of coal. Today, fly ash is widely used for the production of concrete and cement. Its utilization in other industrial areas may bring economic and ecological benefits. Some previously published studies [1-4] assert that fly ash can be used as an additive in ceramic materials and may completely substitute other, more expensive, raw components, since the chemical composition of fly ash $\left(\mathrm{SiO}_{2}, \mathrm{Al}_{2} \mathrm{O}_{3}, \ldots\right)$ is similar to the chemical composition of ceramics. Moreover, fly ash consists of small particles (usually less than $100 \mu \mathrm{m}$ ) and no extra milling or other modifications are needed. Such ceramic materials can be used e.g. for the production of tiles or bricks.

During firing, in ceramic body a number of physical, chemical and phase changes occur resulting, in turn, in a significant change of mechanical and other physical properties of the green body [5-7]. Due to the different characteristics (e.g. different coefficients of thermal expansion) of components of the raw ceramic mixture, rapid volume changes and relaxation of internal stresses are also frequently present and are characteristically accompanied by the formation of elastic waves propagating through the volume of ceramic body. In this study, the acoustic emission ( $\mathrm{AE}$ ) technique is used to detect such waves and thus identify and describe the abovementioned processes. The AE has previously proven to be an efficient research tool in the real time monitoring of the processes occurring within the ceramic body subjected to temperature changes $[8,9]$.

${ }^{*}$ corresponding author; e-mail: knapek@karlov.mff.cuni.cz
Contemporary research in the field of ceramics is primarily focused on basic thermal analyses which provide information about phase development and kinetics of reactions during firing, but mechanical properties, in spite of their importance for ceramics, are only rarely measured as a function of temperature during firing.

In this paper, we focus on the influence of heating rate on the stress-release processes in illite-fly ash ceramic mixture using a distinctive in situ $\mathrm{AE}$ technique. The $\mathrm{AE}$ results are correlated to the results obtained by several thermal analyses (differential thermal analysis - DTA, thermodilatometry - TD, thermogravimetry - TG). In this way, the $\mathrm{AE}$ analysis helps to understand mechanical and physical properties of ceramic materials in their full complexity.

\section{Experimental \\ 2.1. Raw materials}

As a plastic compound of the ceramic mixture a material with major part of illite ( $80 \mathrm{wt} . \%)$ - the most common non-kaolinite ceramic mineral, and various impurities was used (for simplicity hereafter referred to as illite). During thermal treatment, illite content decreases and a glassy phase and a small amount of mullite are formed (Table I). Illite fired at $1100^{\circ} \mathrm{C}$ for 90 min was used as a simulation of grog used for ceramics production. Fly ash (pore particles with an equivalent spherical diameter of approximately $30-110 \mu \mathrm{m}$ ) originates from the thermal power plant Nováky, Slovakia and its mineral composition is primarily as follows: quartz, calcite, anhydrite, plagioclase, portlandite, hematite, and mica.

\subsection{Sample preparation}

The raw materials ( $60 \mathrm{wt} . \%$ of illite, $30 \mathrm{wt} . \%$ of fly ash and 10 wt.\% of fired illite) were mixed together to obtain a homogenized mixture. Sufficient amount of water was added in order to create a plastic mass. Thereafter, 
TABLE I

Development of mineral phases of illite fired to different temperatures (in wt.\%).

\begin{tabular}{c|c|c|c|c}
\hline \hline \multirow{2}{*}{ mineral } & \multicolumn{4}{|c}{ Firing temperature $\left[{ }^{\circ} \mathrm{C}\right]$} \\
\cline { 2 - 5 } & green & 650 & 750 & 1100 \\
\hline illite & 80 & 69 & 34 & 0 \\
montmorillonite & 4 & 3 & 4 & 0 \\
muscovite & 0 & 7 & 35 & 0 \\
quartz & 12 & 12 & 11 & 11 \\
orthoclase & 4 & 5 & 4 & 2 \\
sanidine & 0 & 0 & 0 & 4 \\
mullite & 0 & 0 & 0 & 4 \\
amorphous & 0 & 4 & 13 & 79
\end{tabular}

the samples were extruded to cylinders with diameters of $13 \mathrm{~mm}$ and dried freely at laboratory temperature and relative humidity of about $30 \%$.

\subsection{Thermal analyses (DTA, TG and TD)}

Compact samples (length $\sim 15 \mathrm{~mm}$ ) cut from the dried cylindrical samples were used for the DTA and TG measurements using the upgraded Derivatograph [10]. The volume changes of the samples were monitored using a horizontal dilatometer (details available in [11]). The analyses were performed from room temperature up to $1100^{\circ} \mathrm{C}$ with a heating rate of $5 \mathrm{~K} / \mathrm{min}$.

\subsection{Acoustic emission}

The experimental setup is shown in Fig. 1. A cylindrical sample with length of $60 \mathrm{~mm}$ was mounted to the end of an alumina rod, which served as a waveguide to route $\mathrm{AE}$ out of the furnace. A piezoelectric AE transducer MST8S (diameter $3 \mathrm{~mm}$, flat response in a frequency band from 100 to $600 \mathrm{kHz}$, fabricated by DAKEL ZD Rpety, Czech Republic) was glued to the opposite end of the rod. A computer-controlled DAKEL-XEDO-3 AE system (DAKEL ZD Rpety, Czech Republic) was used to monitor AE. The total gain was $89 \mathrm{~dB}$, the signal

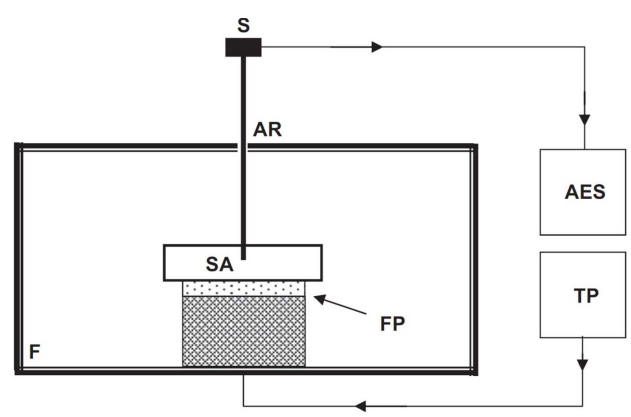

Fig. 1. Experimental set-up for the AE measurements. $\mathrm{SA}=$ sample, $\mathrm{AR}=$ alumina $\operatorname{rod}($ diameter $3 \mathrm{~mm})$, $\mathrm{FP}=$ alumina fiber pad, $\mathrm{S}=\mathrm{AE}$ sensor, $\mathrm{F}=$ furnace, $\mathrm{TP}=$ temperature regulator, $\mathrm{AES}=$ acoustic emission system DAKEL-XEDO-3. sampling rate was $4 \mathrm{MHz}$ and the full scale of the $\mathrm{A} / \mathrm{D}$ converter was $2.4 \mathrm{~V}$. The first threshold voltage (level 1) was set to $302 \mathrm{mV}$, i.e. slightly above the noise level and the second (level 2) threshold voltage to detect the burst AE signal was $600 \mathrm{mV}$.

\section{Results and discussion}

In order to examine the influence of heating rate on the $\mathrm{AE}$ response, the measurements were carried out at three constant heating rates $2.5,5$, and $10 \mathrm{~K} / \mathrm{min}$. In each case, the sample was heated up to $1100^{\circ} \mathrm{C}$. The $\mathrm{AE}$ response at two threshold levels was qualitatively very similar and the AE count rates were scaled almost equally $(\sim 70 \%$ lower at level 2 in each case), therefore, only the data recorded at level 1 are presented. The results are shown in Fig. 2a-c. By comparing these figures, it can be seen that the AE signal is rather low for the heating rates 2.5 and $5 \mathrm{~K} / \mathrm{min}$ and intense for $10 \mathrm{~K} / \mathrm{min}$. Stresses induced by the greater thermal gradients at higher heating rates can be a rich source of the acoustic signals. Higher AE count rate can be explained either by longer duration of individual $\mathrm{AE}$ events or by the detection of overlapping AE. It can be seen in Table II that the mean duration of AE events is quite constant $(\sim 900 \mu \mathrm{s})$ at different heating rates, while the total number of $\mathrm{AE}$ events is considerably higher at $10 \mathrm{~K} / \mathrm{min}$. Moreover, the mean time between two individual events, although significantly lower at $10 \mathrm{~K} / \mathrm{min}$, is larger by several orders of magnitude in comparison with the event duration. Consequently, it is unlikely that the overlapping of $\mathrm{AE}$ events occurs and higher $\mathrm{AE}$ count rate at the heating rate $10 \mathrm{~K} / \mathrm{min}$ may be ascribed to an increased generation of short-duration events within the sample. Such a quantitative analysis of the AE measurement is, however, always uncertain to some extent due to the rather inhomogeneous character of tested samples. Therefore, a qualitative approach will be preferred for the AE signal analysis.

TABLE II

Total number of $\mathrm{AE}$ events, mean event duration and mean time between individual events at three different heating rates $(2.5,5$ and $10 \mathrm{~K} / \mathrm{min})$.

\begin{tabular}{c|c|c|c|c|c}
\hline \hline \multirow{2}{*}{$\begin{array}{c}\text { heating } \\
\text { rate }\end{array}$} & $\begin{array}{c}\text { tot. no. } \\
\text { of events }\end{array}$ & \multicolumn{2}{|c|}{$\begin{array}{c}\text { event } \\
\text { duration }[\mu \mathrm{s}]\end{array}$} & \multicolumn{2}{c}{$\begin{array}{c}\text { time between } \\
\text { events }[\mathrm{s}]\end{array}$} \\
\cline { 3 - 6 } & & av. & med. & av. & med. \\
\hline $2.5\left[\frac{\mathrm{K}}{\mathrm{min}}\right]$ & 167 & 936.63 & 841 & 139.78 & 63.8 \\
$5\left[\frac{\mathrm{K}}{\mathrm{min}}\right]$ & 95 & 873.71 & 846 & 110.62 & 38.78 \\
$10\left[\frac{\mathrm{K}}{\mathrm{min}}\right]$ & $\mathbf{3 3 3}$ & 997.61 & 846 & $\mathbf{1 7 . 3 4}$ & $\mathbf{5 . 1 4}$
\end{tabular}

The AE measurement at a heating rate of $5 \mathrm{~K} / \mathrm{min}$ was also complemented by the thermal analysis methods (Figs. 3-5; AE data are scaled from Fig. 2b). At the beginning (up to $\sim 250{ }^{\circ} \mathrm{C}$ ), a significant decrease of mass $(\sim 4 \%)$ was observed, which is related to the liberation of physically bound water [8]. This process correlates with an endothermic reaction that appears on the DTA curve in Fig. 4 and a slight contraction of the sample in Fig. 5. 


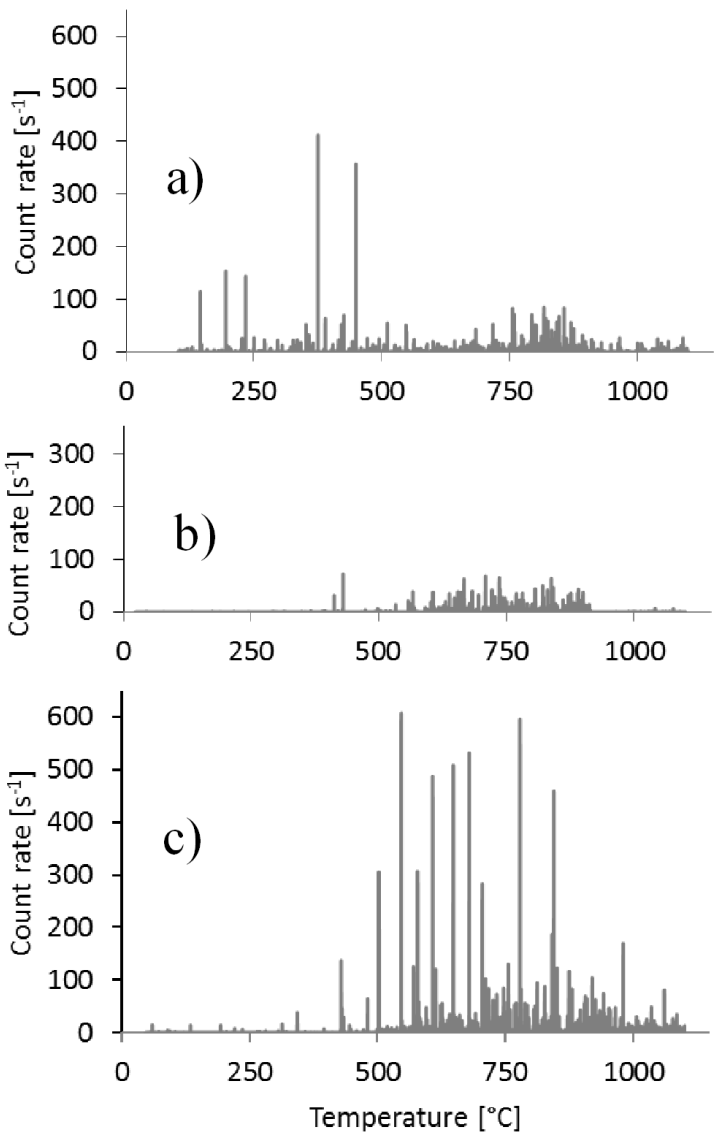

Fig. 2. Acoustic emission activity at three different heating rates a) $2.5 \mathrm{~K} / \mathrm{min}$, b) $5 \mathrm{~K} / \mathrm{min}$, c) $10 \mathrm{~K} / \mathrm{min}$.

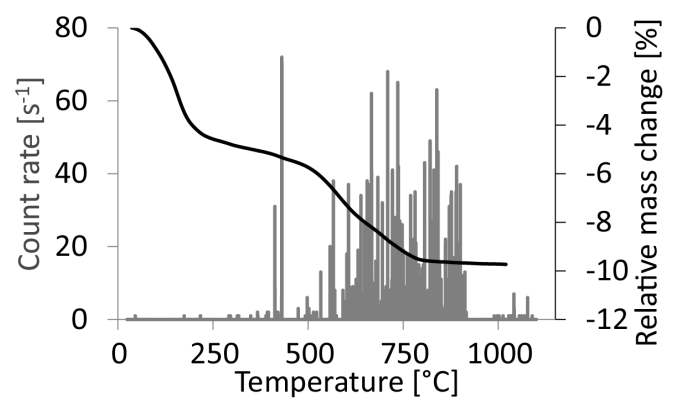

Fig. 3. Mass changes (black line) and AE activity at heating rate $5 \mathrm{~K} / \mathrm{min}$.

On the other hand, no correlations with $\mathrm{AE}$ analysis were found related to this effect. First AE response appears at $\sim 430^{\circ} \mathrm{C}$. It is a region of thermal decomposition of the mineral portlandite $\left(\mathrm{CaOH}_{2}\right)$ as a component of fly ash (a small endotherm in Fig. 4). The $\alpha-\beta$ transformation of quartz (a component of fly ash and impurity in illite), which takes place at $\sim 573{ }^{\circ} \mathrm{C}$, is not visible by DTA, TD and AE, whereas it is concealed by dehydroxylation [8]. In the temperature range $600-900{ }^{\circ} \mathrm{C}$ a very intense $\mathrm{AE}$ was detected. At $600^{\circ} \mathrm{C}$ dehydroxylation has

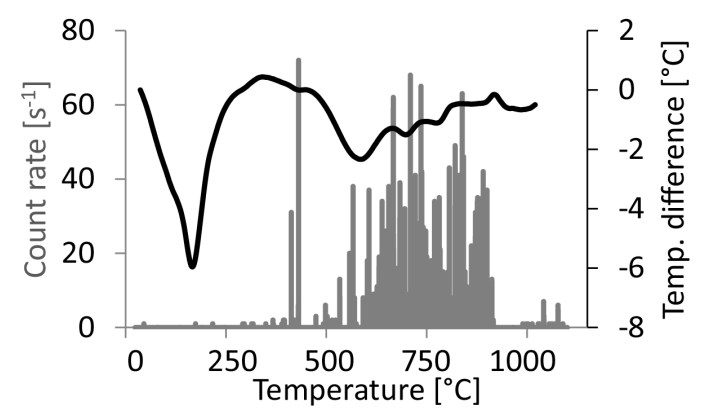

Fig. 4. DTA curve (black line) and AE activity at heating rate $5 \mathrm{~K} / \mathrm{min}$.

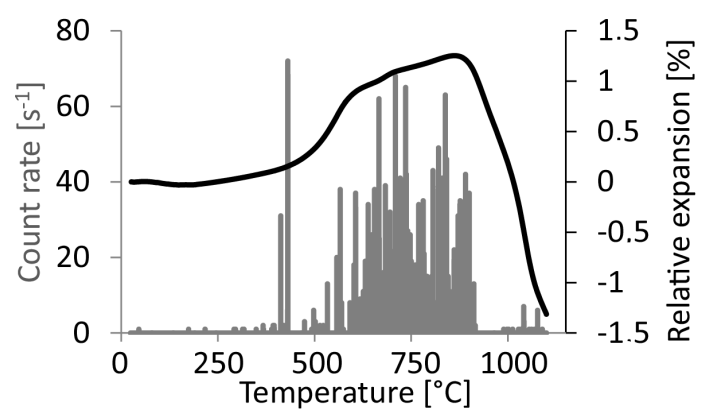

Fig. 5. Thermodilatometric curve (black line) and AE activity at heating rate $5 \mathrm{~K} / \mathrm{min}$.

its maximum on the DTA curve (Fig. 4). The AE count rate also correlates quite well with the expansion of sample at given temperature range (Fig. 5). Another possible source of the $\mathrm{AE}$ signals can be the pressure of the water steam in the pores on the crystals. From $800^{\circ} \mathrm{C}$, the AE source is the thermal decomposition of calcite $\left(\mathrm{CaCO}_{3}\right)$. The AE can be also ascribed to the stresses induced by the difference in thermal expansion of particular minerals. From $\sim 920^{\circ} \mathrm{C}$ we observe decreasing $\mathrm{AE}$ activity. After the dehydroxylation of illite, the glassy phase begins to form. Owing to the relatively low viscosity of the pyroplastic glassy phase, the internal stresses are easily accommodated, which lead to a considerable decrease of the AE activity. The shrinkage of the sample slows down and only weak $\mathrm{AE}$ activity is detected at $\sim 1050^{\circ} \mathrm{C}$ (point of inflexion on the TD curve in Fig. 5). The glassy phase which separates the solid particles fills pores and particles get closer until they "touch". The contact of rigid crystals may result in resuming of internal stresses and the AE signals appear again.

\section{Conclusions}

Heating rate characteristics play an important role for practical applications of ceramic materials and production costs. An intense $\mathrm{AE}$ was recorded at $10 \mathrm{~K} / \mathrm{min}$ suggesting massive mechanical processes within the material at higher rates, while at lower rates 2.5 and $5 \mathrm{~K} / \mathrm{min}$ the $\mathrm{AE}$ voltage level is relatively low. $\mathrm{AE}$ was also 
successfully applied as a complementary method to conventional thermal analyses. The first significant AE response appears at $\sim 430^{\circ} \mathrm{C}$, which is the region of thermal decomposition of portlantide (a component of fly ash). The $\alpha-\beta$ transformation of quartz at $\sim 573{ }^{\circ} \mathrm{C}$ was not detected by DTA, TD or AE as it is concealed by dehydroxylation, which has its maximum at $600{ }^{\circ} \mathrm{C}$. Dehydroxylation together with relatively high expansion of the sample gives rise to the $\mathrm{AE}$ activity up to $900^{\circ} \mathrm{C}$. From 800 to $900^{\circ} \mathrm{C}$ the $\mathrm{AE}$ is also related to the decomposition of calcite and induced thermal stresses. The AE signal attenuates from $920^{\circ} \mathrm{C}$ due to the low viscosity of the amorphous phase. At $\sim 1050{ }^{\circ} \mathrm{C}$ the glassy phase fills pores. Consequently, the crystals are put closer and the $\mathrm{AE}$ activity is resumed upon their contact.

\section{Acknowledgments}

This work was supported by the research grant P108/11/1267 financed by the Czech Science Foundation and by the grant VEGA $1 / 0162 / 15$ from the Ministry of Education of the Slovak Republic. M.K. gratefully acknowledges financial support from the grant SVV2014-269303 and the Grant Agency of Charles University (grant No. 946213).

\section{References}

[1] I. Queralt, X. Querol, A. López-Soler, F. Plana, Fuel 76, 787 (1997).

[2] A. Olgun, Y. Erdogan, Y. Ayhan, B. Zeybek, Ceram. Int. 31, 153 (2005).

[3] R. Sokolář, L. Smetanová, Ceram. Int. 36, 215 (2010).

[4] R. Sokolář, L. Vodová, Ceram. Int. 37, 2879 (2011).

[5] Z. Pospíšil, A. Koller, Fine Ceramics, Basics of Technology, SNTL/ALFA, Prague 1981 (in Czech).

[6] J. Hlaváč, Fundamentals of Silicates Technology, SNTL/ALFA, Prague 1981 (in Czech).

[7] V. Hanykýř, J. Kutzendorfer, Technology of Ceramics, Silis Praha and Vega Hradec Králové, Prague 2000 (in Czech).

[8] I. Štubňa, F. Chmelík, A. Trník, P. Šín, Ceram. Int. 38, 6919 (2012).

[9] F. Chmelík, A. Trník, J. Pešička, I. Stubn̆a, J. Eur Ceram. Soc. 31, 2205 (2011).

[10] R. Podoba, A. Trník, ź. Podobník, Epitönyag 64, 28 (2012).

[11] I. Štubňa, A. Vážanová, G. Varga, D. Hrubý, in: Proc. Research and Teaching of Physics on the Context of University Education, SPU Nitra 2007, p. 59. 